\title{
Reliability of synovial fluid alpha-defensin and leukocyte esterase in diagnosing periprosthetic joint infection (PJI): a systematic review and meta-analysis
}

\author{
Yisheng Chen ${ }^{1 \dagger}$, Xueran Kang ${ }^{2 \dagger}$, Jie Tao ${ }^{3 *}$, Yunpeng Zhang ${ }^{1}$, Chenting Ying ${ }^{1}$ and Weiwei Lin $^{4}$
}

\begin{abstract}
Background: Synovial fluid proteins had been applied as diagnostic biomarkers for periprosthetic joint infection (PJI) in recent research papers. Thus, this meta-analysis aimed to estimate the diagnostic efficiency of synovial fluid a-defensin and leukocyte esterase (LE) for PJI.

Methods: We conducted our systematic review by searching the keywords in online databases such as PubMed, Embase, Cochrane, Elsevier, Springer, and Web of Science from the time of database inception to October 2018. Inclusion criteria were as follows: patients who have undergone knee, hip, or shoulder joint replacements; adefensin or leukocyte esterase (LE strip) of synovial fluid was detected as the biomarker for PJI diagnosis; and Musculoskeletal Infection Society (MSIS) or utilizing a combination of clinical data was considered as the gold standard. Diagnostic parameters including sensitivity, specificity, diagnostic odds ratio (DOR), and area under the summary of receiver operating characteristics curve (AUSROC) were calculated for the included studies to evaluate the synovial fluid a-defensin and LE for PJI diagnosis.

Results: After full-text review, 28 studies were qualified for this systematic review, 16 studies used a-defensin and the other 12 were conducted using LE strip. The pooled sensitivity, specificity, and DOR of LE strip were 87\% (95\% Cl 84-90\%), 96\% (95\% Cl 95-97\%), and 170.09 (95\% Cl 97.63-296.32), respectively, while the pooled sensitivity, specificity, and DOR of a-defensin were 87\% (95\% Cl 83-90\%), 97\% (95\% Cl 96-98\%), and 158.18 (95\% Cl 74.26336.91), respectively. The AUSROC for LE strip and a-defensin were 0.9818 and 0.9685 , respectively.
\end{abstract}

Conclusion: Both LE strip and a-defensin of synovial fluid provide rapid and convenient diagnosis for PJl. Sensitivity of a-defensin and LE strip are the same, while both these two methods have high specificity in clinical practice.

Keywords: a-Defensin, Leukocyte esterase, Periprosthetic joint infection, Meta

\section{Introduction}

Periprosthetic joint infection (PJI) is a challenging problem that exerts significantly negative influence on patients' life after total joint arthroplasty [1, 2]. For a painful joint after surgery, the ability to differentiate between PJI and aseptic loosening is of great significance since the treatment for these two situations are completely different.

\footnotetext{
* Correspondence: taojie123@sjtu.edu.cn

†Yisheng Chen and Xueran Kang contributed equally to this work.

${ }^{3}$ Department of Orthopedics, Shanghai General Hospital, Shanghai Jiao Tong University School of Medicine, Shanghai, China

Full list of author information is available at the end of the article
}

The latter situation requires a second-stage surgery to eradicate the infecting organisms [3].

Traditional routine test includes white blood cell (WBC) number, erythrocyte sedimentation rate (ESR), serum C-reactive protein (CRP), and synovial fluid culture, all of which are non-specific for PJI [4]. In addition, several orthopedic associations have established clinical guidelines based on consensus approaches, expert opinions, and reviews [5]. The American Academy of Orthopedic Surgeons (AAOS) guideline, which was released in 2010 [6], and Musculoskeletal Infection Society (MSIS) guideline $[7,8]$ helped to standardize and

(c) The Author(s). 2019 Open Access This article is distributed under the terms of the Creative Commons Attribution 4.0 International License (http://creativecommons.org/licenses/by/4.0/), which permits unrestricted use, distribution, and reproduction in any medium, provided you give appropriate credit to the original author(s) and the source, provide a link to the Creative Commons license, and indicate if changes were made. The Creative Commons Public Domain Dedication waiver (http://creativecommons.org/publicdomain/zero/1.0/) applies to the data made available in this article, unless otherwise stated. 

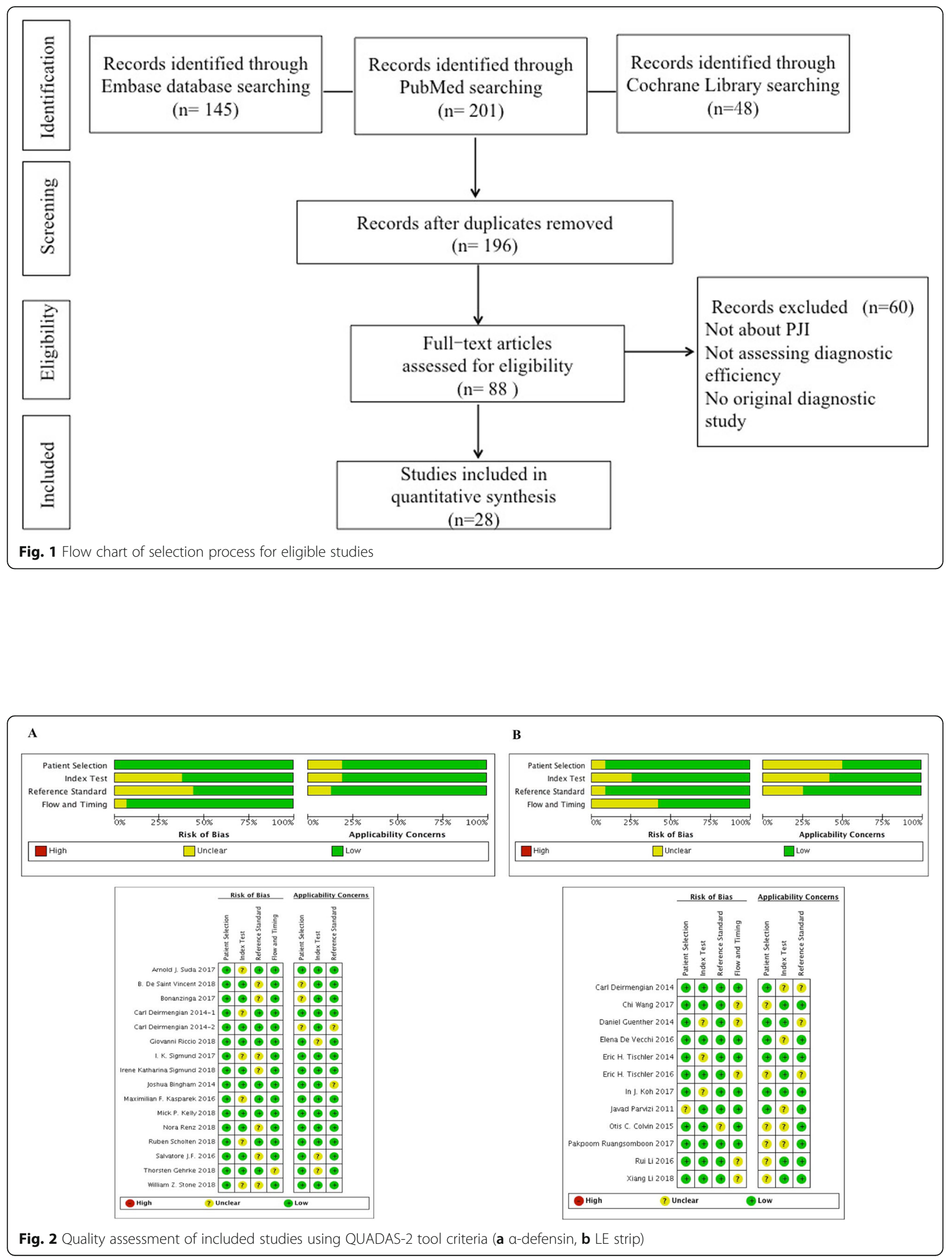
facilitate the diagnostic process for PJI. In 2018, a new definition of PJI was released [8] including several synovial fluid biomarkers, for instance, leukocyte esterase (LE) and $\alpha$-defensin. Although both these two guidelines provide clinicians a standard for PJI diagnosis, they incorporate several criteria, which make them still difficult to execute in daily clinical practice. Thus, if a single or a combination of two or three tests could accurately diagnose PJI, the diagnostic efficient would be greatly improved in clinical practice and help clinicians to make next stage treatment plan. $\alpha$-Defensin and LE strip are two biomarkers that are studied most widely for PJI diagnosis.

$\alpha$-Defensin is an antimicrobial peptide which originates from neutrophils after its response to pathogens [9]. It has been reported that an $\alpha$-defensin test can identify culture-negative infections [10]. Through interacting with the pathogens' cell membrane, it can lead to depolarization and rapid kill of the pathogen [11, 12]. In addition, $\alpha$-defensin are not influenced by antibiotic administration for the treatment of PJIs before diagnostic evaluation. It has been reported that $\alpha$-defensin level did not suffer from a decrease with antimicrobial administration [13]. Compared with the MSIS criteria, which requires a serious of laboratory parameters, $\alpha$-defensin immunoassay could make the diagnosis of PJI more simple and effective. Drago et al. [14] has reported that the specificity of $\alpha$-defensin immunoassay is quite high for excluding the PJI after total hip arthroplasty (THA) and/ or total knee arthroplasty (TKA). In addition, increased $\alpha$-defensin level may be due to reasons other than a periprosthetic infection. The advantages of this test include its convenience and standardization, while a disadvantage is its relatively high cost per test [15].

Leukocyte esterase (LE) is an enzyme produced by activated neutrophils at the site of infection [16]. Detection

Table 1 Characteristics of 16 studies applying alpha-defensin for meta-analysis

\begin{tabular}{|c|c|c|c|c|c|c|c|c|}
\hline Study, year & Country & $\begin{array}{l}\text { Participants } \\
(\mathrm{M} / \mathrm{F})\end{array}$ & $\begin{array}{l}\text { Median age } \\
\text { (range, years) }\end{array}$ & $\begin{array}{l}\text { Study } \\
\text { design }\end{array}$ & $\begin{array}{l}\text { Detection } \\
\text { method }\end{array}$ & Assay platform & $\begin{array}{l}\text { Cutoff } \\
\text { value }\end{array}$ & $\begin{array}{l}\text { Gold } \\
\text { standard }\end{array}$ \\
\hline $\begin{array}{l}\text { Bingham et al. } \\
2014\end{array}$ & USA & UA & UA & $\mathrm{R}$ & ELISA & Synovasure (CD Diagnostics) & $\begin{array}{l}7.72 \\
\mathrm{mg} / \mathrm{L}\end{array}$ & MSIS \\
\hline $\begin{array}{l}\text { Deirmengian } \\
\text { et al. 2014-1 }\end{array}$ & USA & $70 / 79$ & $65(41-89)$ & $P$ & ELISA & Hycult Biotech (Uden, the Netherlands) & $\begin{array}{l}5.2 \\
\mathrm{mg} / \mathrm{L}\end{array}$ & MSIS \\
\hline $\begin{array}{l}\text { Deirmengian } \\
\text { et al. 2014-2 }\end{array}$ & USA & $44 / 51$ & $66(41-86)$ & $P$ & ELISA & Hycult Biotech (Uden, The Netherlands) & $\begin{array}{l}4.8 \\
\mathrm{mg} / \mathrm{L}\end{array}$ & MSIS \\
\hline $\begin{array}{l}\text { Frangiamore } \\
\text { SJ } 2016\end{array}$ & USA & $53 / 63$ & $63(51-79)$ & $P$ & ELISA & Synovasure (CD Diagnostics) & $\begin{array}{l}5.2 \\
\mathrm{mg} / \mathrm{L}\end{array}$ & MSIS \\
\hline $\begin{array}{l}\text { Kasparek et al. } \\
2016\end{array}$ & USA & UA & $71(41-91)$ & $\mathrm{R}$ & $\begin{array}{l}\text { Lateral flow } \\
\text { test }\end{array}$ & Synovasure (CD Diagnostics) & UA & MSIS \\
\hline Suda et al. 2017 & Germany & $17 / 11$ & $67.7(39-88)$ & $P$ & $\begin{array}{l}\text { Lateral flow } \\
\text { test }\end{array}$ & $\begin{array}{l}\text { Synovasure }{ }^{\mathrm{TM}} \text { PJI Test (Zimmer, Warsaw, } \\
\text { IN) }\end{array}$ & UA & MSIS \\
\hline $\begin{array}{l}\text { Bonanzinga et al. } \\
2017\end{array}$ & Germany & $66 / 90$ & UA & $P$ & Immunoassay & Synovasure (CD Diagnostics) & UA & MSIS \\
\hline $\begin{array}{l}\text { Sigmund et al. } \\
2017\end{array}$ & Austria & $22 / 28$ & $65(20-89)$ & $P$ & $\begin{array}{l}\text { Lateral flow } \\
\text { test }\end{array}$ & Synovasure & UA & MSIS \\
\hline $\begin{array}{l}\text { de Saint Vincent } \\
\text { et al. } 2018\end{array}$ & France & $24 / 15$ & UA (35-78) & $P$ & $\begin{array}{l}\text { Lateral flow } \\
\text { test }\end{array}$ & Synovasure ${ }^{\mathrm{TM}},($ Zimmer, Warsaw, IN) & UA & MSIS \\
\hline Kelly et al. 2018 & USA & $21 / 18$ & $64(33-88)$ & $\mathrm{R}$ & Immunoassay & CD Diagnostics & UA & MSIS \\
\hline $\begin{array}{l}\text { Scholten et al. } \\
2018\end{array}$ & Netherlands & $22 / 15$ & $66(51-81)$ & $P$ & $\begin{array}{l}\text { Lateral flow } \\
\text { test }\end{array}$ & Synovasure ${ }^{\mathrm{TM}},($ Zimmer, Warsaw, IN) & UA & Culture \\
\hline Gehrke et al. 2018 & Germany & $77 / 114$ & UA & $P$ & $\begin{array}{l}\text { Lateral flow } \\
\text { test }\end{array}$ & Synovasure kit & UA & MSIS \\
\hline $\begin{array}{l}\text { Sigmund et al. } \\
2018\end{array}$ & Germany & $38 / 33$ & $70(41-85)$ & $\mathrm{R}$ & $\begin{array}{l}\text { Lateral flow } \\
\text { test/ELISA }\end{array}$ & $\begin{array}{l}\text { Synovasure kit (Zimmer Biomet)/ } \\
\text { Synovasure }^{\text {TM }} \text { (CD Diagnostics) }\end{array}$ & UA & $\begin{array}{l}\text { MSIS/ } \\
\text { EBJIS/IDSA }\end{array}$ \\
\hline Riccio et al. 2018 & Italy & $30 / 45$ & $68.7(57-79)$ & $\mathrm{R}$ & $\begin{array}{l}\text { Lateral flow } \\
\text { test }\end{array}$ & Synovasure (CD Diagnostics) & UA & MSIS \\
\hline Stone et al. 2018 & USA & $78 / 105$ & $65.7(34-91)$ & $P$ & Microarray & Synovasure (CD Diagnostics) & UA & MSIS \\
\hline Renz et al. 2018 & Germany & $61 / 106$ & $70(41-94)$ & $P$ & $\begin{array}{l}\text { Lateral flow } \\
\text { test }\end{array}$ & Synovasure kit (Zimmer Biomet) & UA & MSIS \\
\hline
\end{tabular}


of LE has traditionally been used to help diagnose urinary tract infection [17]. The LE in synovial fluid is detected by colorimetric strip tests through reactions, which produces a color change. Advantages of this test include quickness, convenience, and low cost. Due to its convenience, LE strip has been studied during the past several years for diagnosis of PJI. However, several issues has been aroused since then, such as the color change of the strip is frequently affected by blood and the cutoff value for PJI is not in consensus. Thus, more research is still required to solve these problems.

Due to the great heterogeneity of diagnostic criteria, protocols, and sample sizes in publicized papers, the diagnostic utility of these synovial fluid biomarkers has no clear consensus. With the increased use of synovial fluid biomarkers, the diagnostic efficiencies, economic advantages, and limitations have to be taken into consideration. Thus, we conducted a systematic review to summarize studies related to $\alpha$-defensin and LE. We conducted a meta-analysis to investigate the diagnostic accuracy of these two methods in PJI. We aim to compare the diagnostic efficiency of these two most frequently used methods in clinical practice and provide clinicians with more accurate evidence.

\section{Material and methods}

Data from the selected studies were extracted, and eligible studies were assessed by means of the revised Quality Assessment of Diagnostic Accuracy Studies (QUADAS-2) criteria [18]. Statistical analysis, evidence synthesis, and report compilation were carried out as the steps below. We strictly adhered to standards of the Preferred Reporting Items for Systematic Reviews and Meta-Analyses (PRISMA) in reporting the findings of this review (Additional file 1: Table S1 for PRISMA detailed checklist).

\section{Search strategy}

We searched the electronic databases including PubMed, Embase, Web of Science, the Cochrane Library, and Science Direct since the release of MSIS definition to September 2018. Vocabulary and syntax were adjusted according to different databases. We used key words or Mesh words as follows: "periprosthetic joint infection"

Table 2 Characteristics of 13 studies applying leukocyte esterase (LE) strip for meta-analysis

\begin{tabular}{|c|c|c|c|c|c|c|c|}
\hline Study, year & Country & $\begin{array}{l}\text { Participants } \\
(\mathrm{M} / \mathrm{F})\end{array}$ & $\begin{array}{l}\text { Median age } \\
\text { (range, years) }\end{array}$ & $\begin{array}{l}\text { Standard } \\
\text { reference }\end{array}$ & $\begin{array}{l}\text { Study } \\
\text { design }\end{array}$ & Assay platform & $\begin{array}{l}\text { Cutoff } \\
\text { value }\end{array}$ \\
\hline $\begin{array}{l}\text { Parvizi et al. } \\
2011^{\&}\end{array}$ & USA & UA (108) & UA & $\begin{array}{l}\text { Own } \\
\text { institute }\end{array}$ & $P$ & $\begin{array}{l}\text { Chemstrip } 7 \text { urine test strip (Roche Diagnostics, } \\
\text { Indianapolis, Indiana) }\end{array}$ & $++(+)^{*}$ \\
\hline $\begin{array}{l}\text { Tischler et al. } \\
2014\end{array}$ & USA & $90 / 99$ & $63(22-90)$ & MSIS & $P$ & UA & $++(+)^{*}$ \\
\hline $\begin{array}{l}\text { Deirmengian } \\
\text { et al. } 2014^{\zeta}\end{array}$ & USA & $28 / 18$ & $63 / 67$ & MSIS & $\mathrm{R}$ & $\begin{array}{l}\text { Chemstrip } 7 \text { urine test strip (Roche Diagnostics, } \\
\text { Indianapolis, IN) }\end{array}$ & $++/+$ \\
\hline $\begin{array}{l}\text { Guenther et al. } \\
2014^{\&}\end{array}$ & Germany & UA (353) & $67(56-78)$ & MSIS & $P$ & Roche Diagnostics GmbH, Mannheim, Germany & $++/+$ \\
\hline $\begin{array}{l}\text { Colvin et al. } \\
2015^{\&}\end{array}$ & USA & $27 / 30$ & $69.1(31-91)$ & AAOS & $P$ & $\begin{array}{l}\text { Chemstrip } 7 \text { urine test strips (Roche Diagnostics, } \\
\text { Indianapolis, IN) }\end{array}$ & ++ \\
\hline $\begin{array}{l}\text { Tischler et al. } \\
2016\end{array}$ & USA & $30 / 31$ & $64.1(45-80)$ & MSIS & $P$ & UA & ++ \\
\hline $\begin{array}{l}\text { De Vecchi et al. } \\
2016\end{array}$ & Italy & UA (129) & $64(17-88)$ & MSIS & $P$ & Dirui Industrial Co Ltd., China & $++/+$ \\
\hline $\begin{array}{l}\text { Ruangsomboon } \\
\text { et al. } 2017\end{array}$ & Thailand & $11 / 35$ & $69(61-77)$ & ICM criteria & $\mathrm{R}$ & $\begin{array}{l}\text { Chemstrip } 10 \text { urine test strip; Roche Diagnostics, } \\
\text { Indianapolis, Indiana }\end{array}$ & ++ \\
\hline Koh et al. 2017 & Korea & $13 / 47$ & $71(50-85)$ & MSIS & $P$ & $\begin{array}{l}\text { AUTION ELEVEN, ARKRAY, Kyoto, Japan; Clinitek 500, } \\
\text { Siemens, Munich, Germany; and Urisys 2400, Roche } \\
\text { Diagnostics, Mannheim, Germany }\end{array}$ & ++ \\
\hline Li et al. 2017 & China & $27 / 36$ & $57.2(22-80)$ & MSIS & $P$ & Comber 10 Test M Roche (Germany) & ++ \\
\hline Wang et al. 2017 & China & UA & $63(51-75)$ & MSIS & $\mathrm{R}$ & $\begin{array}{l}\text { Combur10 TestM Roche, Germany; AUTION Sticks, } \\
\text { Arkray, Kyoto, Japan }\end{array}$ & ++ \\
\hline Li et al. 2018 & China & $81 / 117$ & $62(48-76)$ & MSIS & $P$ & AUTION Sticks, Arkray, Kyoto, Japan & $++/+$ \\
\hline
\end{tabular}

UA unavailable, $P$ prospective study, $R$ retrospective study, ELISA enzyme-linked immunosorbent assay, ICM International Consensus Meeting

*Both ++ and $++/+$ as cutoff value were analyzed for the sensitivity, specificity, positive predictive value, and negative predictive value

"Similar to MSIS

\&Blood samples excluded

'Both bloody and non-bloody samples were analyzed for the sensitivity, specificity, positive predictive value, and negative predictive value, but only non-bloody

samples were included in the meta-analysis 


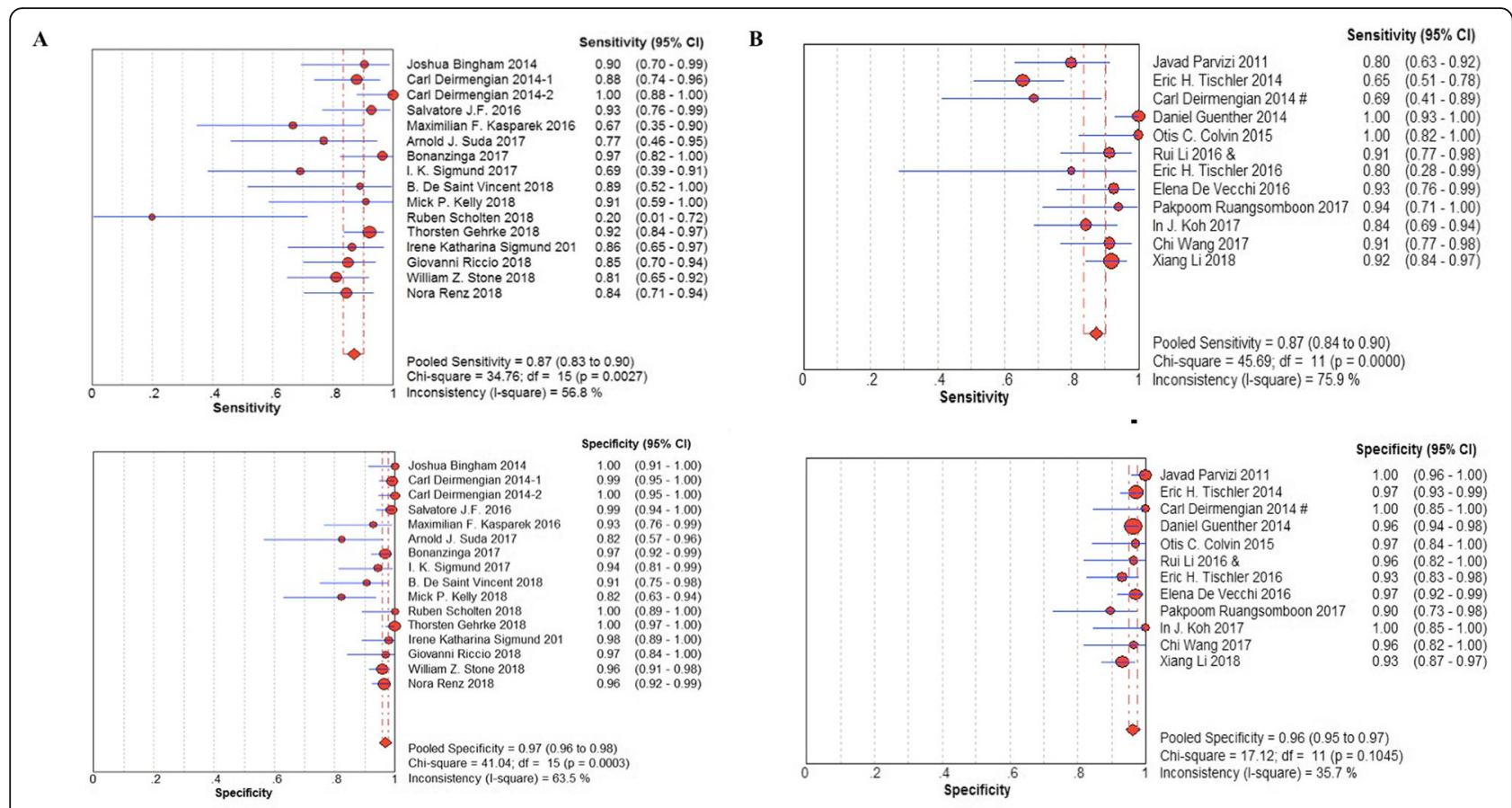

Fig. 3 Pooled sensitivity and specificity for the included studies with the associated 95\% confidence interval (a a-defensin, b LE strip)

or "prosthesis-related infections" to represent the disease, "synovial fluid" or "fluid, synovial" to represent the source of our target biomarker, and " $\alpha$-defensin" or "alpha defensin" or "defensin" or "leukocyte esterase" as our target index.

\section{Study selection}

Screening was performed as follows. Two researchers firstly independently reviewed the title and abstract of each assay to select papers, which require full-text screening. In the initial stage of the screening, ten

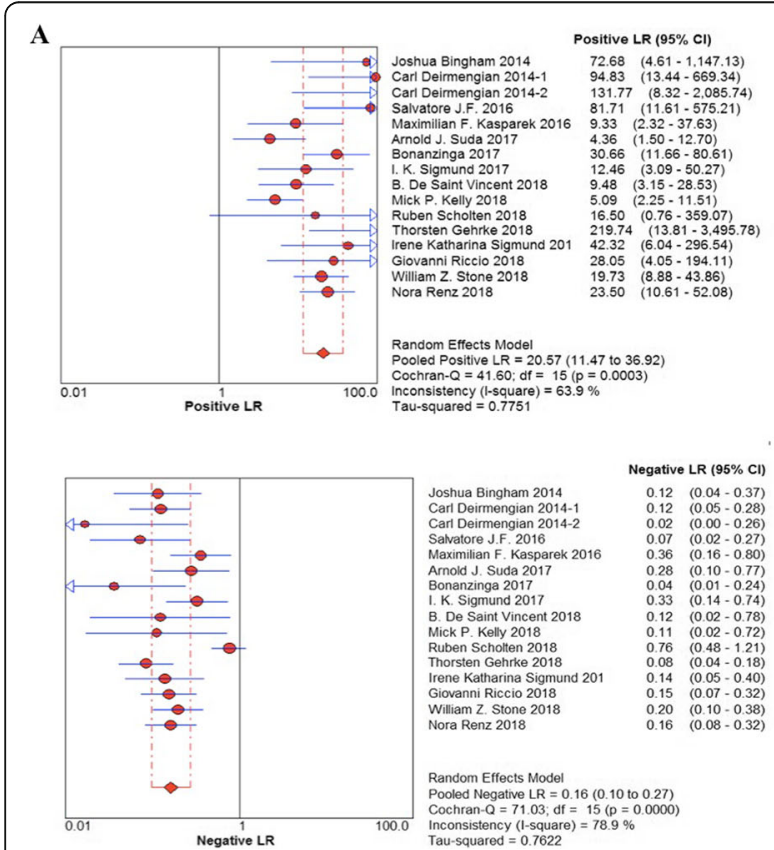

B
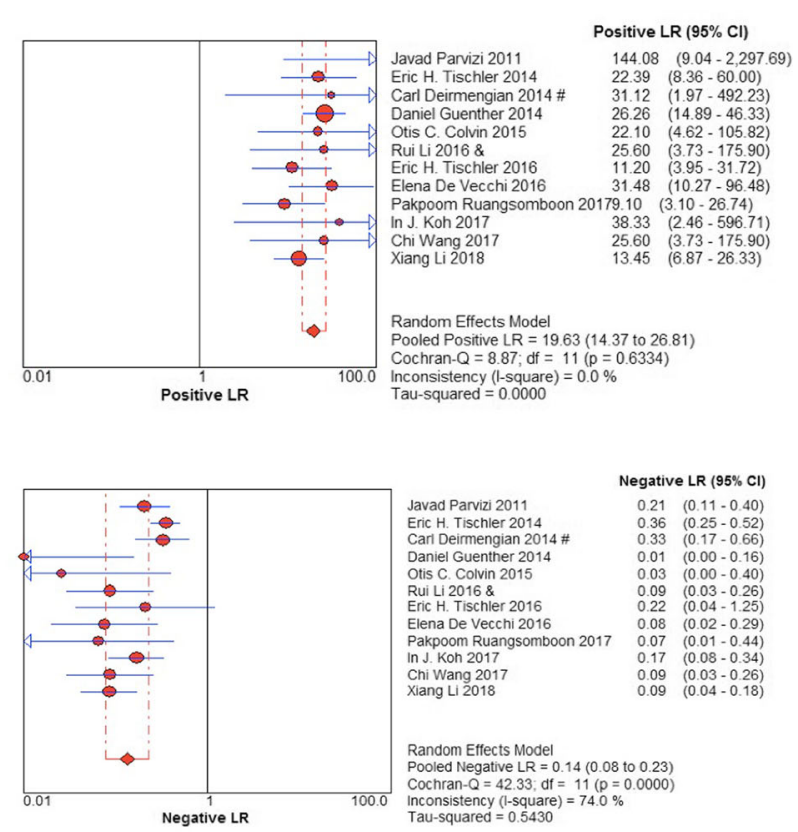

Fig. 4 Positive likelihood ratio (PLR) and negative likelihood ratio (NLR) for the included studies with the associated 95\% confidence interval (a adefensin, $\mathbf{b}$ LE strip) 
articles should be used to confirm the agreement between the researchers. When confronted with disagreements, two researchers had to come to a consensus about the screening standard. After full- text screening, a list of reasons for exclusion was performed.

Inclusion criteria were as follows: patients who have undergone knee, hip, or shoulder joint replacements; 1

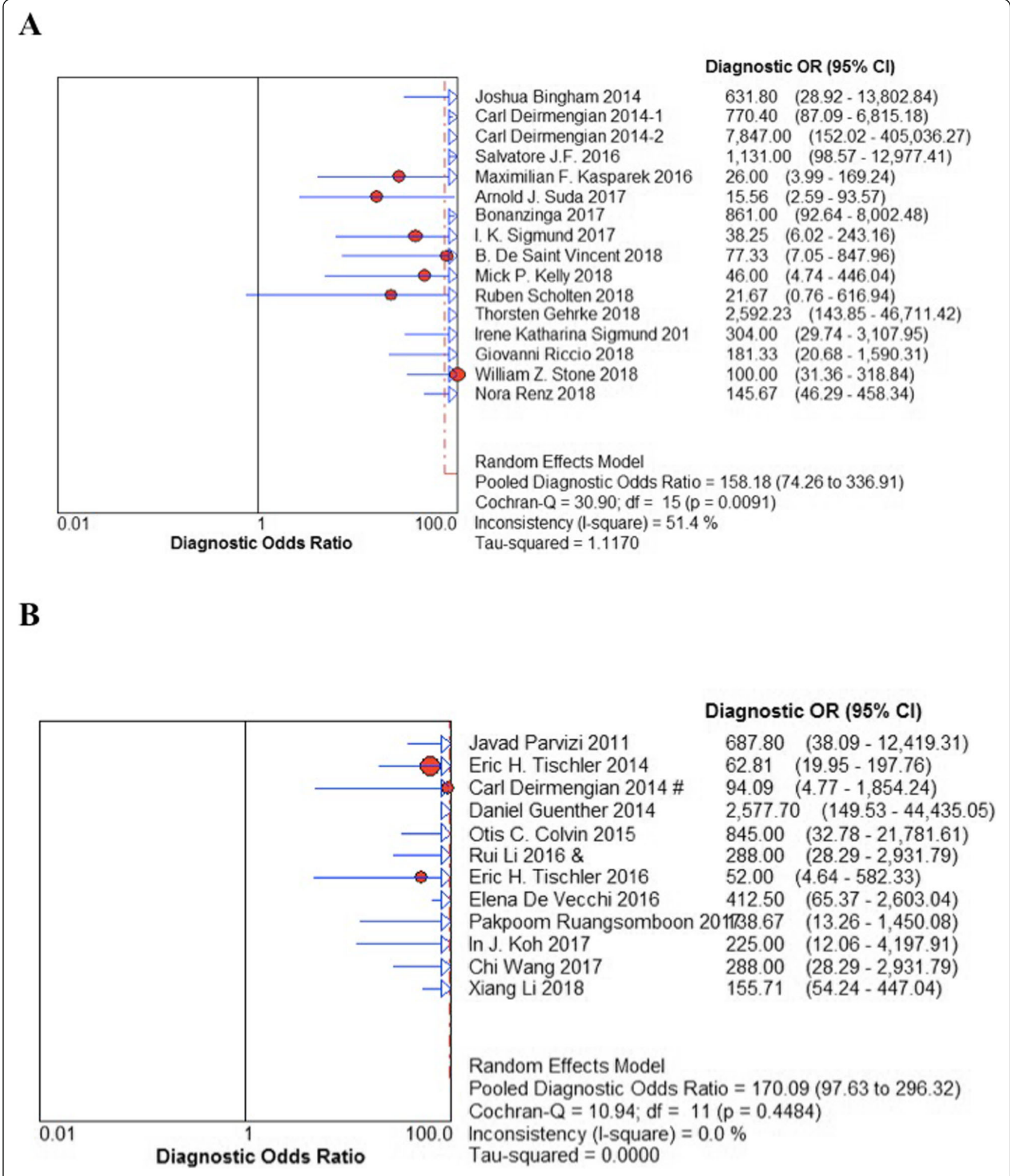

Fig. 5 Diagnostic OR for the included studies with the associated 95\% confidence interval (a a-defensin, b LE strip) 


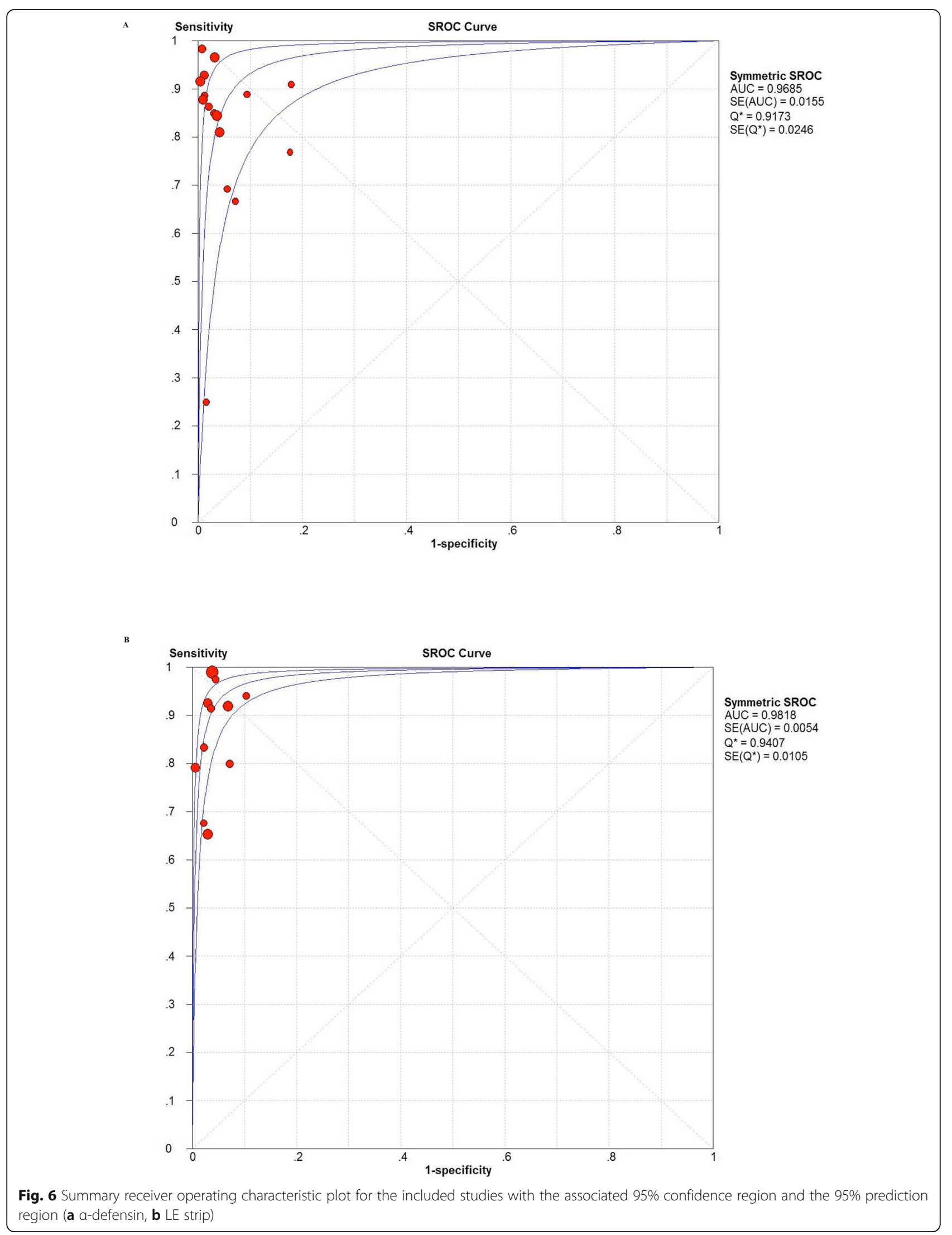


$\mathrm{ml}$ synovial fluid had to be aspirated for study; synovial fluid $\alpha$-defensin or LE strip was determined as the biomarker for PJI diagnosis; Musculoskeletal Infection Society (MSIS) or utilizing a combination of clinical data was considered as the gold standard; and sufficient data could be extracted for the construction of a $2 \times 2$ contingency table. Studies that lacked sensitivity and specificity values were also excluded.

\section{Quality assessment}

The methodological quality of the included studies was appraised by an adapted version of the QUADAS-2, which are composed of four key domains (patient selection, index test, reference standard, and flow and timing). Signaling questions were applied to evaluate the risk of bias and clinical applicability. These questions were responded as "yes" for low risk of bias/concerns, "no" for high risk of bias/concerns, or "unclear".

\section{Data extraction}

The detailed information of qualified studies was extracted: (i) study characteristics including author, year of publication, country, design, and sample size; (ii) population characteristics including patients' mean age, sex, location of joint replacement, and body mass index (BMI); (iii) intervention characteristics including method of sampling, method of measuring, and threshold; (iv) gold standard including the text results based on the definition of PJI by MSIS; (v) outcomes of tested biomarkers such as number of false positive, true positive, false negative, and true negative; and diagnostic parameters such as sensitivity, specificity, positive likelihood ratio $(\mathrm{LR}+)$, and negative likelihood(LR-).

\section{Statistical analysis and heterogeneity assessment}

For all the studies from which we constructed the $2 \times 2$ table, pooled diagnostic parameters mentioned above were calculated through the bivariate model. The summarized receiver operating characteristic (SROC) curve was constructed.

In the diagnostic test, heterogeneity was commonly caused by the threshold effect, which was evaluated by Spearman's correlation coefficient. If there were more than one threshold in an article, the threshold with the largest Yourdon index was chosen. The percentage of the total variation across studies was described by the $I^{2}$ statistic, which indicated the existence of significant heterogeneity when the value exceeded $50 \%$. The value of $I^{2}$ ranges from 0 to $100 \%$, with $0 \%$ implying no observed heterogeneity and larger values indicating increasing heterogeneity. For all effect estimates, a value of $p<0.05$ was considered to be statistically significant. All analysis was conducted using Meta-disc software (version 14.0, Zamora et al., Madrid, Spain).

\section{Results}

Of the identified 394 articles, 196 of them were left for further screening after excluded the duplicates. One hundred eight articles were excluded after reading the title and abstract, reasons including inappropriate article type (reviews, comments, or letters). Then, the remaining 88 articles were read through, and 59 were unqualified due to incomplete data for systematic review. Among these included 29 articles, 16 articles [15, 19-33] explored the diagnostic accuracy of $\alpha$-defensin for PJI, while the remaining 12 studies [34-45] explored the diagnostic accuracy of LE strip for PJI. The flow diagram is illustrated in Fig. 1. QUADAS-2 quality assessment for the included studies is shown in Fig. 2.

A total of 1547 patients who applied $\alpha$-defensin and 1384 patients who applied LE strip for diagnosis of PJI were included in this meta-analysis. Among the included studies, 20 were conducted prospectively and the other nine retrospectively. The optimal cutoff value for $\alpha$ defensin was pre-specified in four studies, varying as 7.72 [15], 4.8 [36], and $5.2[20,22] \mathrm{mg} / \mathrm{l}$, respectively, with enzyme-linked immunosorbent assay (ELISA), while the other 12 studies used lateral flow test strip to determine positive result without cutoff value. Detailed characteristics of individual study were summarized in Table $1(\alpha-$ defensin) and Table 2 (LE strip).

The pooled sensitivity and specificity of $\alpha$-defensin were $87 \%$ (95\% CI 83-90\%) and 97\% (95\% CI 96-98\%), respectively, while the pooled sensitivity and specificity of LE strip were $79 \%$ (95\% CI 75-82\%) and 96\% (95\% CI 95-97\%), respectively (Fig. 3). The pooled positive likelihood ratio (PLR) and negative likelihood ratio (NLR) of $\alpha$-defensin and LE strip are illustrated in Fig. 4. The pooled diagnostic odds ratio (DOR) of $\alpha$-defensin and LE were 158.18 (95\% CI 74.26-336.91) and 164.18 (95\% CI 85.81-314.11), respectively (Fig. 5). The areas under the summary of receiver operating characteristics curve (SROC) for LE strip and $\alpha$-defensin were 0.9826 and 0.9685 , respectively (Fig. 6).

There are two methods used for diagnosis of $\alpha$ defensin (ELISA and lateral flow test strip), which have different sensitivities. Thus, we divided these included studies into two subgroups based on the methods used. The pooled diagnostic parameters are illustrated in Table 3. There was substantial heterogeneity among studies: the $I^{2}$ statistics for sensitivity and specificity values of $\alpha$-defensin were $56.8 \%$ and $63.5 \%$, respectively, while the $I^{2}$ statistics for sensitivity and specificity values of LE strip were $92 \%$ and $33.1 \%$, respectively (Figure 7).

\section{Discussion}

Our systematic review indicated that synovial fluid $\alpha$ defensin can be used as a sensitive and specific biomarker in identifying PJI, while LE strip is slightly less 
A
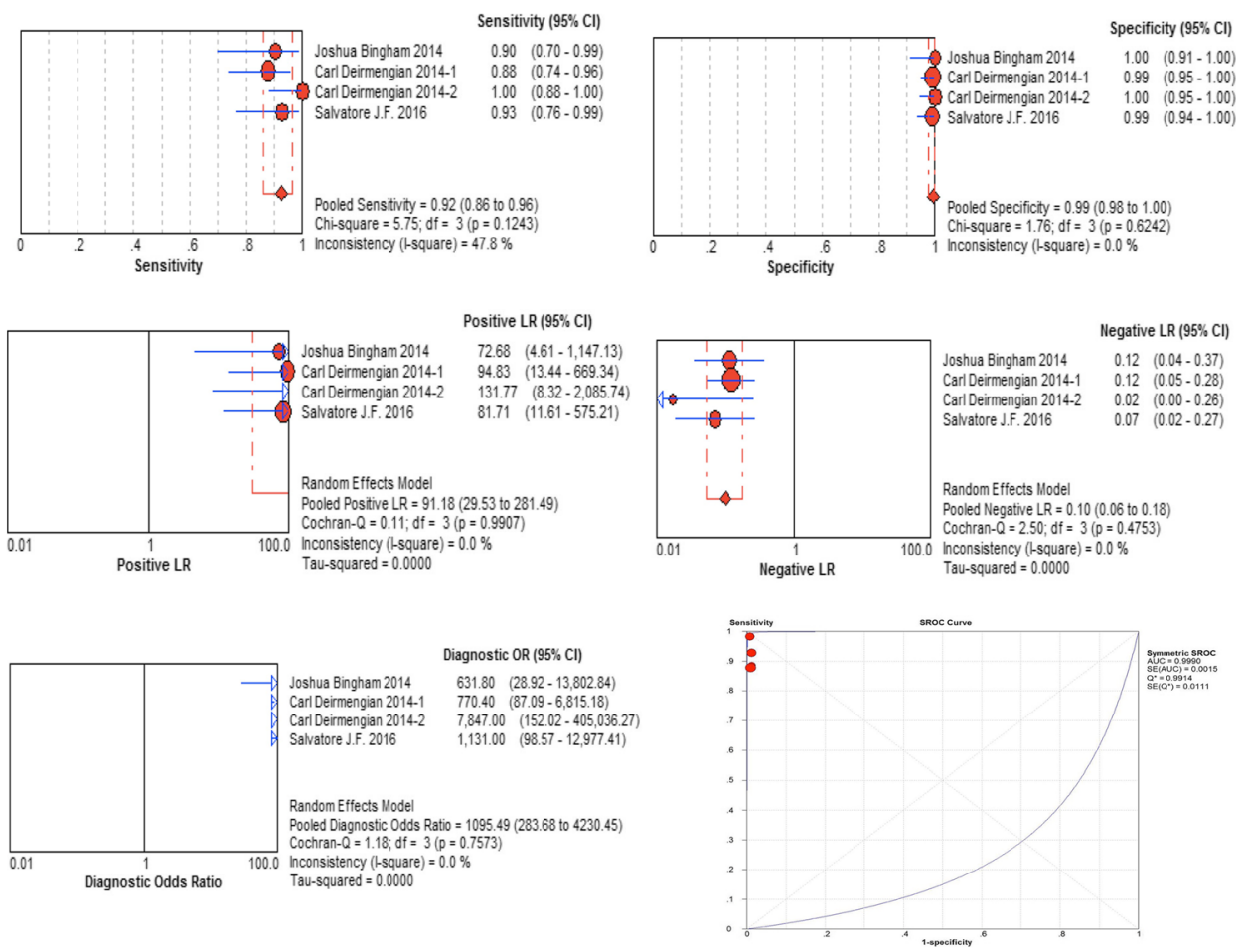

B
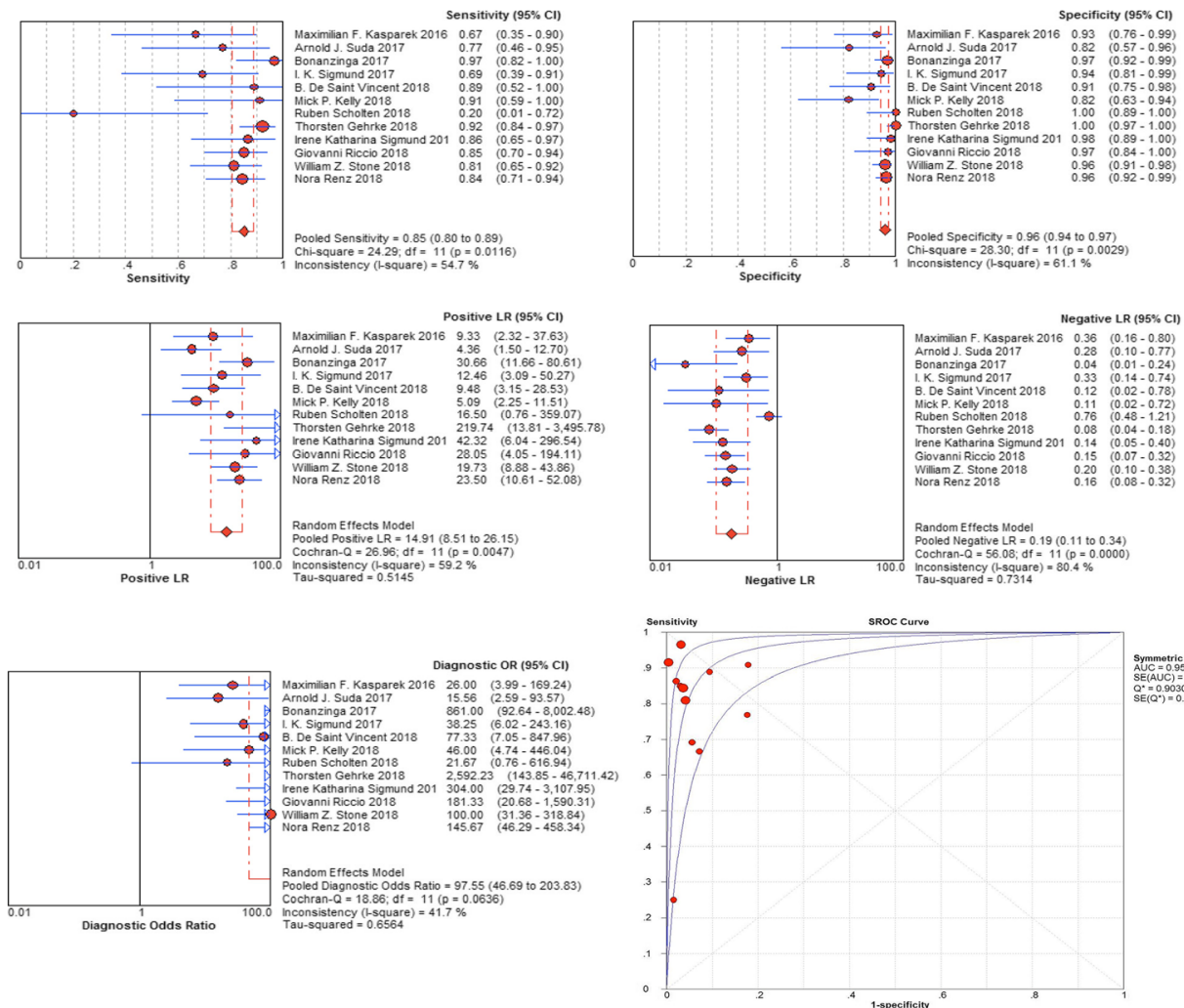

Fig. 7 Pooled diagnostic parameters of enzyme-linked immunosorbert assay (ELISA) (a) and lateral flow test strip (b) for a-defensin A: enzymelinked immunosorbert assay (ELISA), B: lateral flow test strip 
Table 3 Pooled diagnostic parameters of ELISA and lateral flow test strip for a-defensin

\begin{tabular}{lll}
\hline & ELISA & $\begin{array}{l}\text { Lateral flow test } \\
\text { strip }\end{array}$ \\
\hline Number of studies & 4 & 12 \\
Sensitivity $(95 \% \mathrm{Cl})$ & $92 \%(86-96 \%)$ & $85 \%(80-89 \%)$ \\
Specificity $(95 \% \mathrm{Cl})$ & $99 \%(98-100 \%)$ & $96 \%(94-97 \%)$ \\
$\begin{array}{l}\text { Positive likelihood ratio } \\
(95 \% \mathrm{Cl})\end{array}$ & $91.18(29.53-$ & $14.91(8.51-26.15)$ \\
$\begin{array}{l}\text { Negative likelihood ratio }(95 \% \\
\text { Cl) }\end{array}$ & $0.10(0.06-0.18)$ & $0.19(0.11-0.34)$ \\
$\begin{array}{l}\text { Diagnostic odds ratio } \\
(95 \% \mathrm{Cl})\end{array}$ & 1095.49 & 97.55 \\
AUC & $(283.68-4230.45)$ & $(46.69-203.83)$ \\
\hline
\end{tabular}

sensitive but also extremely specific when compared with $\alpha$-defensin. Both these two proteins perform better than other serological and synovial fluid markers (e.g., erythrocyte sedimentation rate [46], synovial fluid procalcitonin [47], synovial fluid interleukin-6 [48], synovial fluid CRP [49]) (Table 4). These biomarkers are frequently affected by other inflammatory diseases such as rheumatic arthritis and osteoarthritis. Therefore, novel biomarkers for PJI diagnosis arise. Our meta-analysis summarized the recently publicized articles related with the diagnosis of PJI with $\alpha$-defensin or LE strip and included the above 29 studies, which in total contains over 3000 patients. Since all studies were publicized after 2011, which is the year that MSIS criteria had been bring into clinical practice, most of the included studies used MSIS as the gold standard. This greatly minimizes classification bias by using the "standard" based on the experience of clinicians in each hospital. Synovial fluid aspirated from patients who have undergone total joint replacement provides researchers with a perfect source of PJI diagnosis. In recent years, research on PJI diagnosis focused on synovial fluid, as it represents the local environment of infection, and diagnosis should be more sensitive than that of serum markers.

Table 4 Diagnostic values of other serum or synovial fluid biomarkers for PJI

\begin{tabular}{lll}
\hline Biomarker & Sensitivity (95\% Cl) & Specificity (95\% Cl) \\
\hline $\begin{array}{l}\text { Erythrocyte sedimentation } \\
\text { rate (ESR) }\end{array}$ & $86 \%(82.5-89 \%)$ & $72.3 \%(70.4-74.2 \%)$ \\
$\begin{array}{l}\text { Serum C-reactive protein } \\
\text { (CRP) }\end{array}$ & $86.9 \%(83.5-89.9 \%)$ & $78.6 \%(86.9-80.3 \%)$ \\
$\begin{array}{l}\text { Synovial fluid procalcitonin } \\
\text { (PCT) }\end{array}$ & $53 \%(24-80 \%)$ & $92 \%(45-99 \%)$ \\
$\begin{array}{l}\text { Synovial fluid CRP } \\
\begin{array}{l}\text { Synovial fluid interleukin-6 } \\
\text { (IL-6) }\end{array}\end{array}$ & $92 \%(86-96 \%)$ & $90 \%(87-93 \%)$ \\
\hline
\end{tabular}

There are several host proteins in synovial fluid with antimicrobial activity, which play an important role in the response to pathogens elimination [50], among which $\alpha$-defensin is considered of great clinical significance. Through searching the currently publicized essays, we found that $\alpha$-defensin test was performed with Synovasure (CD Diagnostics), Synovasure ${ }^{\mathrm{Tx}}$ PJI Test (Zimmer, Warsaw, IN), or Hycult Biotech (Uden, The Netherlands). Through " $\alpha$-defensin flow later" test, synovial fluid is dropped onto the test device and then migrates to the buffering pad to further combine with the specific antibody. It takes about $10 \mathrm{~min}$ for the mixture to across the test line, and then the result is provided to the operator [51]. The main problem confronted with the orthopedic surgeons is that most of them lack the experience and training to evaluate the significance of quality control and proper documentation when using point of care test (POCT) assays.

Among the commonly used biomarkers in synovial fluid for PJI, the urinary LE test strip is inexpensive, convenient, and commercially available. However, since the LE test strip was originally developed for urinary testing, the characteristics in synovial fluid ought to be re-evaluated. According to our current meta-analysis, the main problem of LE strip is that the cutoff value is not determined since it is a colorimetric test and many factors including blood can greatly influence the result. Due to the high rate of blood interference, centrifugation should be performed on synovial fluid samples before they are dropped on the LE strip. The urinary LE tests strip sometime fails to detect LE enzymatic activity, even when there is abundant LE in the synovial fluid. It was attributed to the LE inhibitors in inflamed synovial fluid [52].

However, there are several limitations in our study. Firstly, although we have included 16 studies for $\alpha$ defensin, the detection was based on mainly two companies: Synovasure ${ }^{\text {th }}$ PJI Test (Zimmer, Warsaw, IN) and Synovasure (CD Diagnostics). Since there is still no standard cutoff value for the diagnosis worldwide, different laboratories used different cutoff value to determine the PJI patients, which means large-scale prospective randomized trials are required to address this problem. Several studies of $\alpha$-defensin came from the same research group $[10,20,36]$, which might affect the generalization of our findings. In addition, none of the studies mentioned about blinding and the time point of sampling, which might potentially introduce selection bias. Last but not the least, according to the pooled data, the sensitivity, specificity, and AUC of ELISA were all higher than those of lateral flow test strip. However, the subgroup of ELISA contains merely four studies while the other group contains 12 studies. Thus, more studies with ELISA methods ought to be carried out to further confirm the diagnostic efficiency of this method. 
In conclusion, based on this meta-analysis, $\alpha$-defensin is substantially more expensive (US\$760 per test) than LE strip (US $\$ 0.17$ per test). However, $\alpha$-defensin may be more sensitive in diagnosing PJI, and both tests may have played important roles in PJI diagnosis. Considering all these aspects, the $\alpha$-defensin assay, although representing a convenient method for orthopedics, could not be used as the only marker to rule out PJI. Such situations happen in clinical practice, and it should be integrated with other MSIS criteria so that a more precise and accurate diagnosis could be obtained. Although there are still lots of work to do, our study demonstrated a solid foundation for clinicians to use these simple, prompt, and convenient detection methods to diagnose PJI accurately and efficiently. In the future, development of more simple and convenient point of care tests should be the focus of research efforts.

\section{Supplementary information}

Supplementary information accompanies this paper at https://doi.org/10. 1186/s13018-019-1395-3.

Additional file 1. PRISMA 2009 Checklist.

\begin{abstract}
Abbreviations
AAOS: American Academy of Orthopedic Surgeons; AUSROC: Area under the summary of receiver operating characteristics curve; BMI: Body mass index; CRP: C-reactive protein; DOR: Diagnostic odds ratio; ELISA: Enzyme-linked immunosorbent assay; ESR: Erythrocyte sedimentation rate; LE: Leukocyte esterase; LR: Likelihood ratio; MSIS: Musculoskeletal Infection Society; PJl: Periprosthetic joint infection; QUADAS-2: Quality Assessment of Diagnostic Accuracy Studies; SROC: Summarized receiver operating characteristic; THA: Total hip arthroplasty; THA: Total knee arthroplasty; WBC: White blood cell
\end{abstract}

\section{Acknowledgements}

No acknowledgement.

\section{Authors' contributions}

YC and XK searched and screened assays and extracted the data. YZ and CY performed the statistical analysis. $W L$ and $Y C$ prepared the manuscript. JT conceived the idea. All authors read and approved the final manuscript.

\section{Funding}

This manuscript was supported by China National Nature Science Foundation (No. 81371963).

\section{Availability of data and materials}

All data generated or analyzed during this study are included in this published article.

\section{Ethics approval and consent to participate}

Our study has been approved by the Ethics committee of Shanghai General Hospital, Shanghai Jiao Tong University School of Medicine.

\section{Consent for publication}

Consent for publication was obtained from all participants.

\section{Competing interests}

The authors declare that they have no competing interests.

\section{Author details}

${ }^{1}$ Department of Orthopedics, Shanghai General Hospital, Shanghai Jiao Tong University School of Medicine, Shanghai, China. ${ }^{2}$ Department of
Otolaryngology-Head and Neck Surgery, Shanghai Ninth People' s Hospital, Ear Institute, Shanghai Key Laboratory of Translational Medicine on Ear and Nose Diseases, Shanghai Jiao Tong University School of Medicine, Shanghai, China. ${ }^{3}$ Department of Orthopedics, Shanghai General Hospital, Shanghai Jiao Tong University School of Medicine, Shanghai, China. ${ }^{4}$ Department of Neurosurgery, The First Affiliated Hospital of Wenzhou Medical University, Wenzhou, Zhejiang, China.

Received: 1 July 2019 Accepted: 25 September 2019

Published online: 19 December 2019

\section{References}

1. Dale H, Fenstad AM, Hallan G, Havelin LI, Furnes O, Overgaard S, et al. Increasing risk of prosthetic joint infection after total hip arthroplasty. Acta Orthop. 2012;83(5):449-58.

2. Huotari $K$, Peltola $M$, Jamsen $E$. The incidence of late prosthetic joint infections: a registry-based study of 112,708 primary hip and knee replacements. Acta Orthop. 2015:86(3):321-5.

3. Garvin $\mathrm{KL}$, Konigsberg BS. Infection following total knee arthroplasty: prevention and management. Instr Course Lect. 2012;61:411-9.

4. Workgroup Convened by the Musculoskeletal Infection S. New definition for periprosthetic joint infection. J Arthroplast. 2011;26(8):1136-8.

5. Cats-Baril W, Gehrke T, Huff K, Kendoff D, Maltenfort M, Parvizi J. International consensus on periprosthetic joint infection: description of the consensus process. Clin Orthop Relat Res. 2013;471(12):4065-75.

6. Parvizi J, Della Valle CJ. AAOS Clinical Practice Guideline: diagnosis and treatment of periprosthetic joint infections of the hip and knee. J Am Acad Orthop Surg. 2010;18(12):771-2.

7. Parvizi J, Zmistowski B, Berbari EF, Bauer TW, Springer BD, Della Valle CJ, et al. New definition for periprosthetic joint infection: from the Workgroup of the Musculoskeletal Infection Society. Clin Orthop Relat Res. 201 1;469(11):2992-4.

8. Parvizi J, Tan TL, Goswami K, Higuera C, Della Valle C, Chen AF, et al. The 2018 definition of periprosthetic hip and knee infection: an evidence-based and validated criteria. J Arthroplast. 2018;33(5):1309-14 e2.

9. Ganz T, Selsted ME, Szklarek D, Harwig SS, Daher K, Bainton DF, et al. Defensins. Natural peptide antibiotics of human neutrophils. J Clin Invest. 1985;76(4):1427-35.

10. Deirmengian C, Kardos K, Kilmartin P, Gulati S, Citrano P, Booth RE Jr. The alpha-defensin test for periprosthetic joint infection responds to a wide spectrum of organisms. Clin Orthop Relat Res. 2015;473(7):2229-35.

11. Lehrer Rl, Ganz T. Defensins: endogenous antibiotic peptides from human leukocytes. CIBA Found Symp. 1992;171:276-90 discussion 90-3.

12. Chalifour A, Jeannin P, Gauchat JF, Blaecke A, Malissard M, N'Guyen T, et al. Direct bacterial protein PAMP recognition by human NK cells involves TLRs and triggers alpha-defensin production. Blood. 2004;104(6):1778-83.

13. Shahi A, Parvizi J, Kazarian GS, Higuera C, Frangiamore S, Bingham J, et al. The alpha-defensin test for periprosthetic joint infections is not affected by prior antibiotic administration. Clin Orthop Relat Res. 2016:474(7):1610-5.

14. Drago L, Toscano M, Tacchini L, Banfi G. Alpha-defensin point-of-care test for diagnosis of prosthetic joint infections: neglected role of laboratory and clinical pathologists. Clin Chem Lab Med. 2017;56(1):19-24.

15. Bonanzinga T, Zahar A, Dutsch M, Lausmann C, Kendoff D, Gehrke T. How reliable is the alpha-defensin immunoassay test for diagnosing periprosthetic joint infection? A prospective study. Clin Orthop Relat Res. 2017:475(2):408-15.

16. Kusumi RK, Grover PJ, Kunin CM. Rapid detection of pyuria by leukocyte esterase activity. JAMA. 1981;245(16):1653-5.

17. Scheer WD. The detection of leukocyte esterase activity in urine with a new reagent strip. Am J Clin Pathol. 1987;87(1):86-93.

18. Whiting PF, Rutjes AW, Westwood ME, Mallett S, Deeks JJ, Reitsma JB, et al. QUADAS-2: a revised tool for the quality assessment of diagnostic accuracy studies. Ann Intern Med. 2011;155(8):529-36.

19. Bingham J, Clarke H, Spangehl M, Schwartz A, Beauchamp C, Goldberg B. The alpha defensin-1 biomarker assay can be used to evaluate the potentially infected total joint arthroplasty. Clin Orthop Relat Res. 2014; 472(12):4006-9.

20. Deirmengian C, Kardos K, Kilmartin P, Cameron A, Schiller K, Parvizi J. Combined measurement of synovial fluid alpha-Defensin and C-reactive protein levels: highly accurate for diagnosing periprosthetic joint infection. J Bone Joint Surg Am. 2014;96(17):1439-45. 
21. Deirmengian C, Kardos K, Kilmartin P, Cameron A, Schiller K, Parvizi J. Diagnosing periprosthetic joint infection: has the era of the biomarker arrived? Clin Orthop Relat Res. 2014;472(11):3254-62.

22. Frangiamore SJ, Saleh A, Grosso MJ, Kovac MF, Hiquera CA, lannotti JP, et al. Alpha-defensin as a predictor of periprosthetic shoulder infection. J Shoulder Elb Surg. 2015;24(7):1021-7.

23. Kasparek MF, Kasparek M, Boettner F, Faschingbauer M, Hahne J, Dominkus M. Intraoperative diagnosis of periprosthetic joint infection using a novel alpha-defensin lateral flow assay. J Arthroplast. 2016;31(12):2871-4.

24. Sigmund IK, Holinka J, Gamper J, Staats K, Bohler C, Kubista B, et al. Qualitative alpha-defensin test (Synovasure) for the diagnosis of periprosthetic infection in revision total joint arthroplasty. Bone Joint J. 2017;99-B(1):66-72.

25. Suda AJ, Tinelli M, Beisemann ND, Weil Y, Khoury A, Bischel OE. Diagnosis of periprosthetic joint infection using alpha-defensin test or multiplex-PCR: ideal diagnostic test still not found. Int Orthop. 2017;41(7):1307-13.

26. de Saint VB, Migaud H, Senneville E, Loiez C, Pasquier G, Girard J, et al. Diagnostic accuracy of the alpha defensin lateral flow device (Synovasure) for periprosthetic infections in microbiologically complex situations: a study of 42 cases in a French referral centre. Orthop Traumatol Surg Res. 2018; 104(4):427-31.

27. Gehrke T, Lausmann C, Citak M, Bonanzinga T, Frommelt L, Zahar A. The accuracy of the alpha defensin lateral flow device for diagnosis of periprosthetic joint infection: comparison with a gold standard. J Bone Joint Surg Am. 2018;100(1):42-8.

28. Kelly MP, Darrith B, Hannon CP, Nam D, Courtney PM, Della Valle CJ. Synovial fluid alpha-defensin is an adjunctive tool in the equivocal diagnosis of periprosthetic joint infection. J Arthroplasty. 2018;33(11):3537-40.

29. Renz N, Yermak K, Perka C, Trampuz A. Alpha defensin lateral flow test for diagnosis of periprosthetic joint infection: not a screening but a confirmatory test. J Bone Joint Surg Am. 2018;100(9):742-50.

30. Riccio G, Cavagnaro L, Akkouche W, Carrega G, Felli L, Burastero G. Qualitative alpha-defensin versus the main available tests for the diagnosis of periprosthetic joint infection: best predictor test? J Bone Jt Infect. 2018; 3(3):156-64

31. Scholten R, Visser J, Van Susante JLC, Van Loon CJM. Low sensitivity of adefensin (Synovasure) test for intra-operative exclusion of prosthetic joint infection. Acta Orthop. 2018:89(3):357-9.

32. Sigmund IK, Yermak K, Perka C, Trampuz A, Renz N. Is the enzyme-linked immunosorbent assay more accurate than the lateral flow alpha defensin test for diagnosing periprosthetic joint infection? Clin Orthop Relat Res. 2018;476(8):1645-54

33. Stone WZ, Gray CF, Parvataneni HK, Al-Rashid M, Vlasak RG, Horodyski M, et al. Clinical evaluation of synovial alpha defensin and synovial C-reactive protein in the diagnosis of periprosthetic joint infection. J Bone Joint Surg Am. 2018;100(14):1184-90.

34. Colvin OC, Kransdorf MJ, Roberts CC, Chivers FS, Lorans R, Beauchamp CP, et al. Leukocyte esterase analysis in the diagnosis of joint infection: can we make a diagnosis using a simple urine dipstick? Skelet Radiol. 2015;44(5):673-7.

35. De Vecchi E, Villa F, Bortolin M, Toscano M, Tacchini L, Romano CL, et al. Leucocyte esterase, glucose and C-reactive protein in the diagnosis of prosthetic joint infections: a prospective study. Clin Microbiol Infect. 2016; 22(6):555-60.

36. Deirmengian C, Kardos K, Kilmartin P, Cameron A, Schiller K, Booth RE Jr, et al. The alpha-defensin test for periprosthetic joint infection outperforms the leukocyte esterase test strip. Clin Orthop Relat Res. 2015;473(1):198-203.

37. Guenther D, Kokenge T, Jacobs O, Omar M, Krettek C, Gehrke T, et al. Excluding infections in arthroplasty using leucocyte esterase test. Int Orthop. 2014;38(11):2385-90

38. Parvizi J, Jacovides C, Antoci V, Ghanem E. Diagnosis of periprosthetic joint infection: the utility of a simple yet unappreciated enzyme. J Bone Joint Surg Am. 2011;93(24):2242-8

39. Tischler EH, Cavanaugh PK, Parvizi J. Leukocyte esterase strip test: matched for musculoskeletal infection society criteria. J Bone Joint Surg Am. 2014; 96(22):1917-20.

40. Tischler EH, Plummer DR, Chen AF, Della Valle CJ, Parvizi J. Leukocyte esterase: metal-on-metal failure and periprosthetic joint infection. J Arthroplast. 2016;31(10):2260-3.

41. Koh IJ, Han SB, In Y, Oh KJ, Lee DH, Kim TK, et al. The leukocyte esterase strip test has practical value for diagnosing periprosthetic joint infection after total knee arthroplasty: a multicenter study. J Arthroplast. 2017;32(11):3519-23.
42. Li X, Li R, Ni M, Chai W, Hao L, Zhou Y, et al. Leukocyte esterase strip test: a rapid and reliable method for the diagnosis of infections in arthroplasty. Orthopedics. 2018;41(2):e189-e93.

43. Ruangsomboon P, Chinprasertsuk S, Khejonnit V, Chareancholvanich K. Effect of depth of centrifuged synovial fluid on leukocyte esterase test for periprosthetic joint infection. J Orthop Res. 2017;35(11):2545-50.

44. Wang C, Li R, Wang Q, Duan J, Wang C. Leukocyte esterase as a biomarker in the diagnosis of periprosthetic joint infection. Med Sci Monit. 2017;23: $353-8$.

45. Li R, Li X, Yu B, Li X, Song X, Li H, et al. Comparison of leukocyte esterase testing of synovial fluid with synovial histology for the diagnosis of periprosthetic joint infection. Med Sci Monit. 2017;23:4440-6.

46. Wang C, Wang Q, Li R, Duan JY, Wang CB. Synovial fluid C-reactive protein as a diagnostic marker for periprosthetic joint infection: a systematic review and meta-analysis. Chin Med J. 2016;129(16):1987-93.

47. Xie K, Qu X, Yan M. Procalcitonin and alpha-defensin for diagnosis of periprosthetic joint infections. J Arthroplast. 2017;32(4):1387-94.

48. Xie K, Dai K, Qu X, Yan M. Serum and synovial fluid interleukin-6 for the diagnosis of periprosthetic joint infection. Sci Rep. 2017;7(1):1496.

49. Huerfano E, Bautista M, Huerfano M, Bonilla G, Llinas A. Screening for infection before revision hip arthroplasty: a meta-analysis of likelihood ratios of erythrocyte sedimentation rate and serum C-reactive protein levels. J Am Acad Orthop Surg. 2017;25(12):809-17.

50. Kapadia BH, Berg RA, Daley JA, Fritz J, Bhave A, Mont MA. Periprosthetic joint infection. Lancet. 2016;387(10016):386-94.

51. Zmistowski B, Della Valle C, Bauer TW, Malizos KN, Alavi A, Bedair H, et al. Diagnosis of periprosthetic joint infection. J Arthroplast. 2014;29(2 Suppl): 77-83.

52. Shahi A, Tan TL, Kheir MM, Tan DD, Parvizi J. Diagnosing periprosthetic joint infection: and the winner is? J Arthroplast. 2017;32(9S):S232-S5.

\section{Publisher's Note}

Springer Nature remains neutral with regard to jurisdictional claims in published maps and institutional affiliations.

Ready to submit your research? Choose BMC and benefit from:

- fast, convenient online submission

- thorough peer review by experienced researchers in your field

- rapid publication on acceptance

- support for research data, including large and complex data types

- gold Open Access which fosters wider collaboration and increased citations

- maximum visibility for your research: over $100 \mathrm{M}$ website views per year

At BMC, research is always in progress.

Learn more biomedcentral.com/submissions 